\title{
Ball Milling and Annealing of Co-50 at\% W Powders
}

\author{
A. S. Bolokang ${ }^{1,2^{*}}$, M. J. Phasha ${ }^{2^{*}}$, D. E. Motaung ${ }^{3}$ \\ ${ }^{1}$ Department of Engineering Metallurgy, University of Johannesburg, Johannesburg, South Africa \\ ${ }^{2}$ Transnet Rail Engineering, Pretoria, South Africa \\ ${ }^{3}$ DST/CSIR Nanotechnology Innovation Centre, National Centre of Nano-Structured Materials, \\ Council for Scientific and Industrial Research, Pretoria, South Africa \\ Email: *Amogelang.bolokang@transnet.net, " majay_phasha@yahoo.com
}

Received December 24, 2012; revised March 12, 2013; accepted March 20, 2013

Copyright (C) 2013 A. S. Bolokang et al. This is an open access article distributed under the Creative Commons Attribution License, which permits unrestricted use, distribution, and reproduction in any medium, provided the original work is properly cited.

\begin{abstract}
Broadening and height reduction of X-ray diffraction peaks were observed after cold-pressing of unmilled Co-W powder mixture. It seems the effect of cold pressing has slightly reduced the lattice parameter of W from 3.165 to $3.143 \AA$. Consequent annealing of unmilled compacts yielded metastable phases. Upon 10 and $20 \mathrm{~h}$ ball milling of Co-W powder, no alloying was obtained. Although milling did not yield significant crystal changes in W and Co ground state structures, its effect is evident during subsequent annealing. An eta phase is obtained for the first time from unmilled-annealed Co-W powder mixture in the absence of interstitial elements like carbon, while the milled counterpart yielded the rhombohedral $\mathrm{Co}_{7} \mathrm{~W}_{6}$-type phase with composition deviated from stoichiometric value.
\end{abstract}

Keywords: Ball Milling; Crystal Structure; XRD, Annealing; Co-W Powder

\section{Introduction}

Cobalt-tungsten (Co-W) alloy is a promising material that can be used for among others coatings and corrosion resistance applications. The alloy is often manufactured as thin films produced by deposition [1-4] or magnetron sputtering spanning [5]. Due to rapid cooling involved during deposition and sputtering, formation of novel metastable and amorphous phases is attained. Electrodeposited $\mathrm{Co}-\mathrm{W}$ is a potential candidate to replace $\mathrm{Co}-\mathrm{Cr}$ due to better mechanical properties such as high surface sliding hardness, wear resistance and good ductility [6]. In addition, the processing of $\mathrm{Co}-\mathrm{W}$ system is environmentally friendly compared to $\mathrm{Co}-\mathrm{Cr}$. Some studies reveal that a deposited film of $\mathrm{Co}-\mathrm{W}$ consists of a bi-phasic structure, mainly metastable hexagonal close-packed (HCP) and amorphous phases [6,7]. In some cases, only the existence of amorphous structure is observed $[1,3,8]$. To the best of our knowledge, the study on the influence of ball milling $(\mathrm{BM})$ on $\mathrm{Co}-\mathrm{W}$ powder mixture is still lacking. BM is a versatile solid-state powder synthesizing technique used to produce alloying of powders with reduced crystalline size $[9,10]$. The objective of the current study is to investigate the crystal structure of unmilled and milled Co 50 at $\% \mathrm{~W}$ powder mixtures after annealing.

\footnotetext{
"Corresponding authors.
}

\section{Experimental Procedure}

Commercial $\mathrm{W}$ and Co powders of $99.5 \%$ purity were used during ball milling and cold pressing experiments. The measured particle sizes has percentage particle distribution $\mathrm{D}_{50}=32.40$ and $5.42 \mu \mathrm{m}$ for Co and $\mathrm{W}$, respectively. Milling was conducted in a high-energy ball mill at $650 \mathrm{rpm}$ and 20:1 ball to powder ratio for time intervals of 10 and 20 hours (h). In order to minimize contamination, milling was performed under inert atmosphere with no process control agent (PCA) added. The changes in powder particle morphology were analysed using the LEO 1525 field-emission scanning electron microscope (FE-SEM) coupled with a Robinson Backscatter Electron Detector (RBSD). Phase evolution was traced with a Panalytical X'pert PRO PW 3040/60 x-ray diffractometer (XRD) equipped with a $\mathrm{Cu} \mathrm{K}_{\alpha}$ monochromated radiation source, scanning from $20^{\circ}$ to $90^{\circ}(2 \theta)$ in $0.02^{\circ}$ step size. The crystalline sizes $(D)$ of unpressed and cold-pressed powders were estimated by Williamson-Hall (W-H) equation as follows:

$$
\beta_{h k l} \cos \theta_{h k l}=\frac{k \lambda}{D}+4 \varepsilon \sin \theta_{h k l}
$$

where $\theta$ is the Bragg diffraction angle, $D$ is the average crystalline size, $\varepsilon$ is the average internal strain, $k$ is a constant with a value of $0.9, \lambda=0.154056 \mathrm{~nm}$ is the wavelength for $\mathrm{Cu} \mathrm{K} \alpha$ radiation and $\beta$ is the diffraction 
peak width at half maximum intensity. The average internal strain $(\varepsilon)$ is estimated from the slope of $\beta \cos \theta$ versus $4 \sin \theta$ linear plot, while the average crystalline $(D)$ is estimated from the y-intercept. Annealing of powder compacts was carried out in a Carbolite tube furnace under flowing argon gas at $800^{\circ} \mathrm{C}$ and $1200^{\circ} \mathrm{C}$.

\section{Results and Discussions}

\subsection{Unmilled Co-W Powders}

Shown in Figures 1(a)-(d) is the SEM images of unmilled $\mathrm{Co}, \mathrm{W}$ and milled $\mathrm{Co}-\mathrm{W}$ powder mixture for 10 and $20 \mathrm{~h}$, respectively. The Co particles appear coarse compared to those of $\mathrm{W}$. The mixture of fine and large, flat-round particles is evident on both 10 and $20 \mathrm{~h}$ milled powders. This large particles could be due to agglomeration as a result of cold-welding during milling.

The XRD patterns of the $\mathrm{Co}-\mathrm{W}$ compact after coldpressing, $800^{\circ} \mathrm{C}$ and $1200^{\circ} \mathrm{C}$ annealing are presented in Figures 2(a)-(c). It is evident from Figures 2(a) and (b) that the diffraction peaks belonging to body centered cubic (BCC) $\mathrm{W}$ are more intense compared to those representing HCP and FCC (face centered cubic) Co phases. In

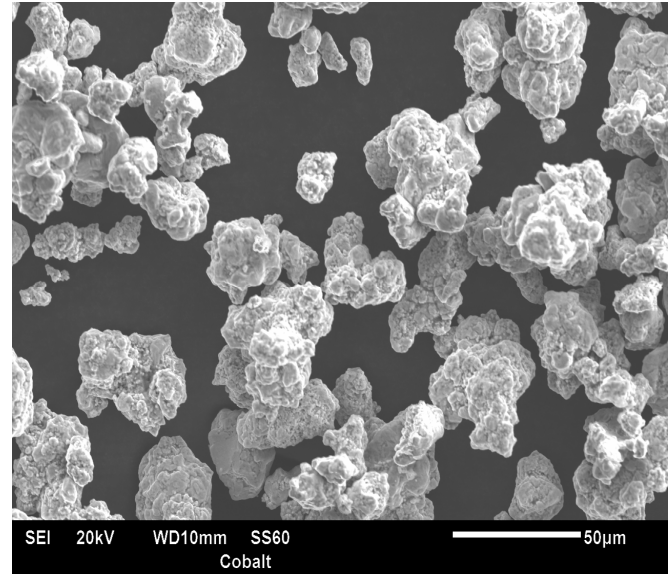

(a)

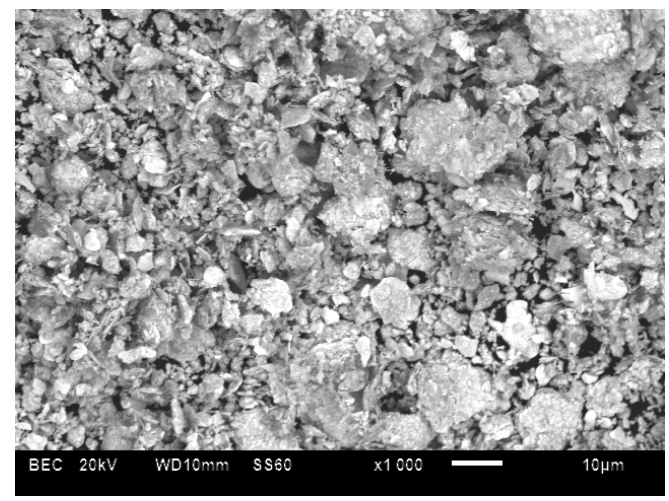

(c) addition, these peaks indicate broadening.

XRD peak widening is well known to be caused by the refinement of particles and sometimes also associated with amorphous phases. However, the lattice parameter of the cold-pressed compact is $3.143 \AA$, smaller than that of pure W $(3.165 \AA)$. It is likely that thereduction of the lattice parameter is due to surface deformation during coldpressing. Moreover, it has been reported that cold pressing can promote structural change on Co $[11,12]$. Although low melting temperature elements such as tin (Sn) and tellurium (Te) mixture were alloyed by repeated coldpressing process [13], it is not logical to expect high melting temperature metals such as $\mathrm{Co}$ and $\mathrm{W}$ to be alloyed by cold-pressing, but their surfaces might be coldwelded. From the XRD analyses of Co-W compacts annealed at $800^{\circ} \mathrm{C}$ and $1200^{\circ} \mathrm{C}$ shown in Figures 2(b) and (c), respectively, it is apparent that the peak broadening observed after cold-pressing was reversed by annealing as shown by sharp peaks. This behaviour is could be attributed to the beginning of sintering effect. In addition to the retained BCC phase with lattice parameter of $3.143 \AA$ after annealing at $800^{\circ} \mathrm{C}, \mathrm{FCC}$ Co with lattice parameter of $3.554 \AA$ was detected, as presented in Table 1 .

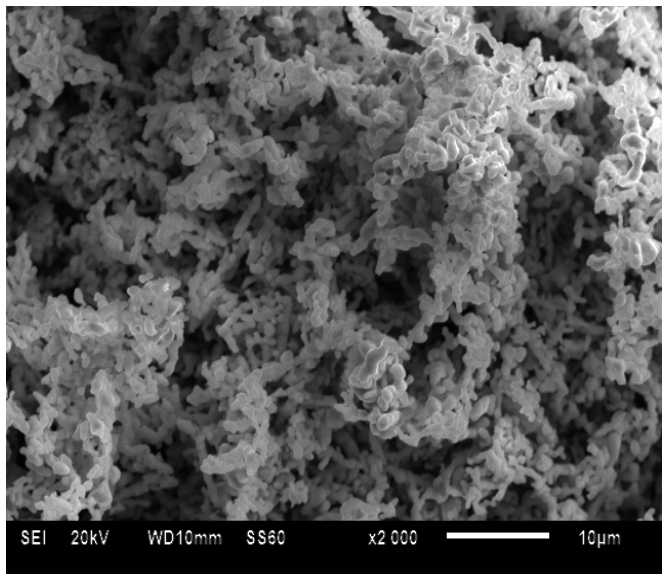

(b)

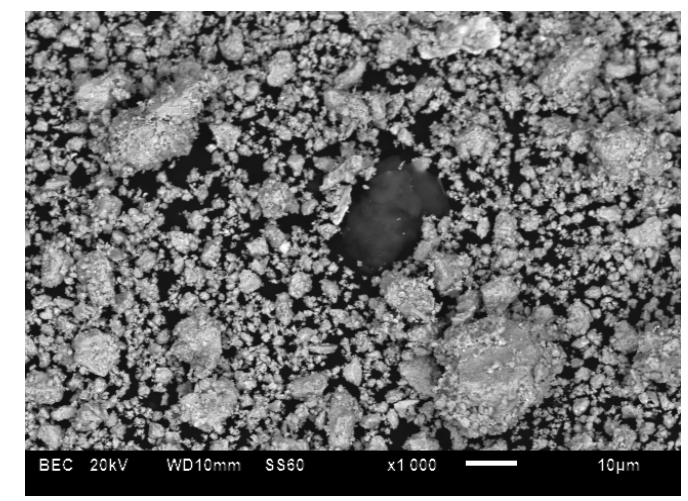

(d)

Figure 1. SEM morphology of unmilled (a) Co and (b) W unmilled powders, and of powder mixture after $10 \mathrm{~h} \mathrm{BM} \mathrm{(c)} \mathrm{and} 20 \mathrm{~h}$ BM (d). 


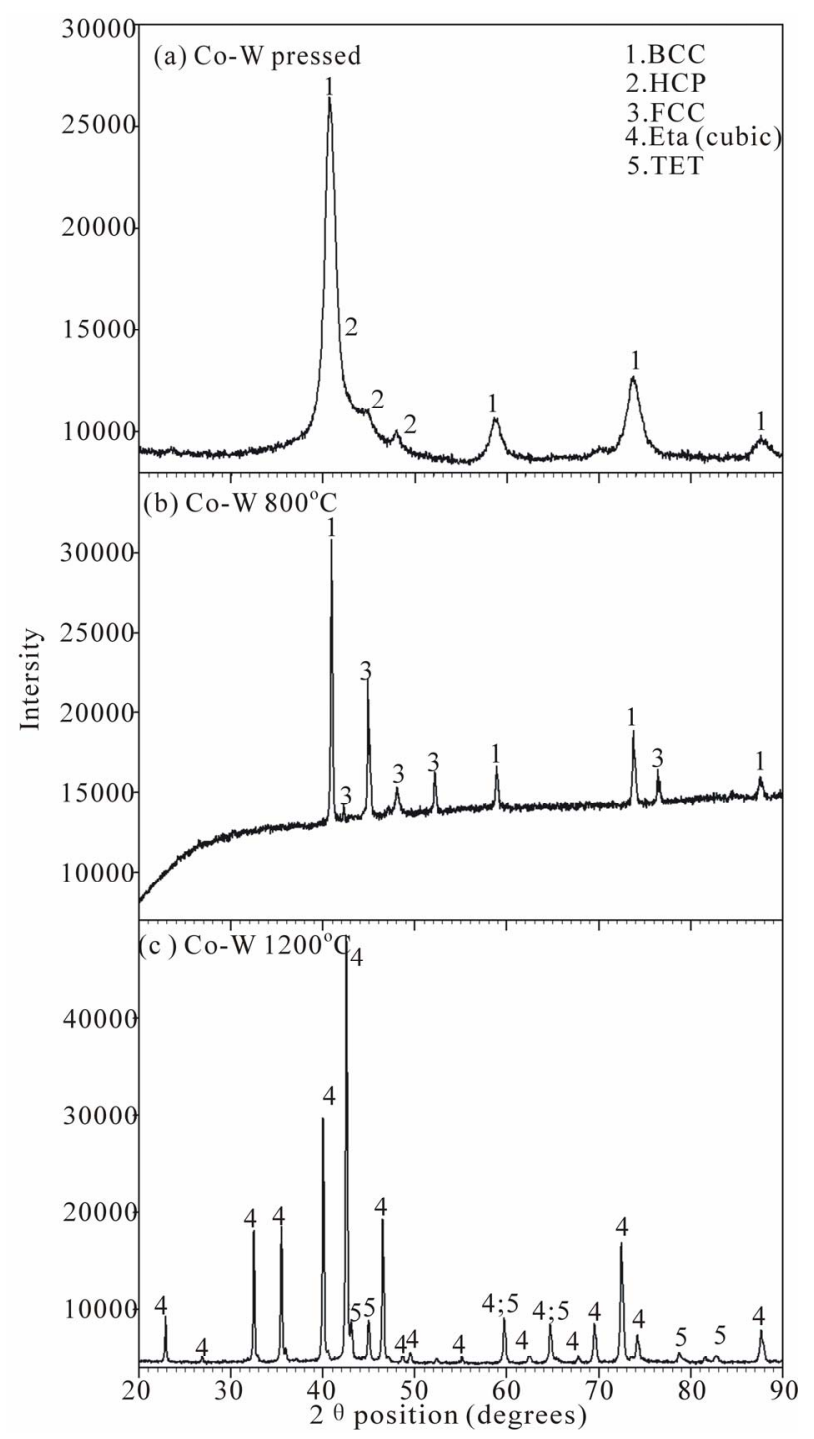

Figure 2. XRD patterns of (a) cold-pressed Co-W powder (b) sintered at $800^{\circ} \mathrm{C}$ and (c) $1200^{\circ} \mathrm{C}$.

Table 1. Experimental XRD data of cold pressed, ball milled and annealed Co-W powders.

\begin{tabular}{cccc}
\hline \multirow{2}{*}{$\begin{array}{c}\text { Sample } \\
\text { condition }\end{array}$} & $\begin{array}{c}\text { Crystal } \\
\text { Structure }\end{array}$ & \multicolumn{2}{c}{ Lattice parameter $(\AA)$} \\
\cline { 3 - 4 } & & $\mathrm{a}$ & $\mathrm{c}$ \\
\hline Co-W pressed & BCC W HCP Co & 3.1432 .514 & 4.105 \\
Co-W 800 & & \\
Co-W $1200^{\circ} \mathrm{C}$ & BCC W FCC Co & 3.1433 .554 & \\
& Eta TET & 11.0902 .850 & 3.091 \\
Co-W 10 h BM BCC W HCP Co & 3.1472 .514 & 4.105 \\
Co-W 20 h BM BCC W HCP Co & 3.1652 .514 & 4.105 \\
Co-W 10 h BM & RHL HCP & $4.751-4.905$ & $25.670-23.787$ \\
$1200^{\circ} \mathrm{C}$ & $2.751-2.764$ & $4.282-4.127$ \\
Co-W 20 h BM & RHL HCP & $4.738-5.021$ & $25.850-25.890$ \\
$1200^{\circ} \mathrm{C}$ & 2.728 & 4.226 \\
\hline
\end{tabular}

A similar FCC phase of about $3.506 \AA$ was obtained in milled $\mathrm{Co}$ annealed at $800^{\circ} \mathrm{C}$ in previous study [14]. Upon annealing $\mathrm{Co}-\mathrm{W}$ compacts at $1200^{\circ} \mathrm{C}$, formation of tetragonal (TET) and FCC superstructure called eta $(\eta)$ phase with space group Fd-3m \# 227 were detected, as indicated in Figure 2(c). Similar phases were obtained and reported as follows: 1) TET phase formed from ball milled W powder compacts annealed at $1200^{\circ} \mathrm{C}$ [15], 2) eta phase obtained from milled and $800^{\circ} \mathrm{C}$ annealed $\mathrm{W}$ [14], W milled and annealed at $730^{\circ} \mathrm{C}$ [16], milled $\mathrm{W}-\mathrm{Ni}$ powder mixture annealed at $730^{\circ} \mathrm{C}$ and $1400^{\circ} \mathrm{C}$ [16] as well as from mixture of separately milled elemental $\mathrm{Co}$ and $\mathrm{W}$ powders compacted and annealed at $800^{\circ} \mathrm{C}$ [14]. The corresponding formation mechanisms were also provided. Although $\eta$-phase has been detected in pure $\mathrm{W}[14,16]$, pre-milled Co-W mixture [14], Ni-W [17] and Ni-Mo materials [18], it does not exist under equilibrium conditionsin any of the above systems including the Co-W, $\mathrm{Ni}-\mathrm{W}$ and Ni-Mo systems in the absence of carbon. Furthermore, it is well known that this phase is unstable and dissociates at high temperatures $[14,19]$. The obtained lattice parameter $(11.090 \AA)$ of $\eta$-phase is larger than that found after reduction of cobalt-tungsten oxide (10.846 $\AA$ ) [20]. The phases obtained in the current study are not found in Co-W equilibrium phase diagram shown in Figure 1 in [14]. They are therefore regarded as metastable or rather intermediate.

\subsection{Ball milled Co-W Powders}

The XRD patterns of 0,10 and $20 \mathrm{~h}$ ball milled Co-W powders are shown in Figures 3(a)-(c). In comparison with the unmilled, the peaks of $10 \mathrm{~h}$ sample are slightly broader and their intensity significantly reduced. Almost similar to the compaction effect, the lattice parameter of BCC W was decreased from 3.165 to $3.147 \AA$ with the estimated crystallite size of about $60 \mathrm{~nm}$, while lattice parameters of HCP Co remained unchanged. Upon $20 \mathrm{~h}$ of $\mathrm{BM}$, the peaks were further broadened and reduced in height. Surprisingly, the undeformed lattice of pure BCC W $(3.165 \AA)$ was recovered. This could imply that BM just reversed the deformation on the surface of $\mathrm{W}$ particles observed on the $10 \mathrm{~h}$ ball-milled powder. Similarly, crystallite size of $\sim 60 \mathrm{~nm}$ was calculated. Since the crystal structure of Co did not change either, it thus follows that no alloying was induced by BM. For alloying to be achieved, high energy is required considering the melting temperatures of both Co and W. Physical properties such as thermal expansion coefficient, melting temperature, activation energy, elastic modulus and yield strength which are $13.4 \times 10^{-6} \mathrm{C}^{-1}, 1495^{\circ} \mathrm{C}, \mathrm{Q}_{\mathrm{B}}=117 \mathrm{KJ} / \mathrm{mol}, 211$ $\mathrm{GPa}$ and $345 \mathrm{MPa}$ for $\mathrm{Co}$, and $4.5 \times 10^{-6} \mathrm{C}^{-1}, 3410^{\circ} \mathrm{C}, \mathrm{Q}_{\mathrm{B}}$ $=385 \mathrm{KJ} / \mathrm{mol}, 411 \mathrm{GPa}$, and $550 \mathrm{MPa}$ in the case of $\mathrm{W}$, respectively [21], also play an important role in order for alloying to occur at approximately room temperature. 


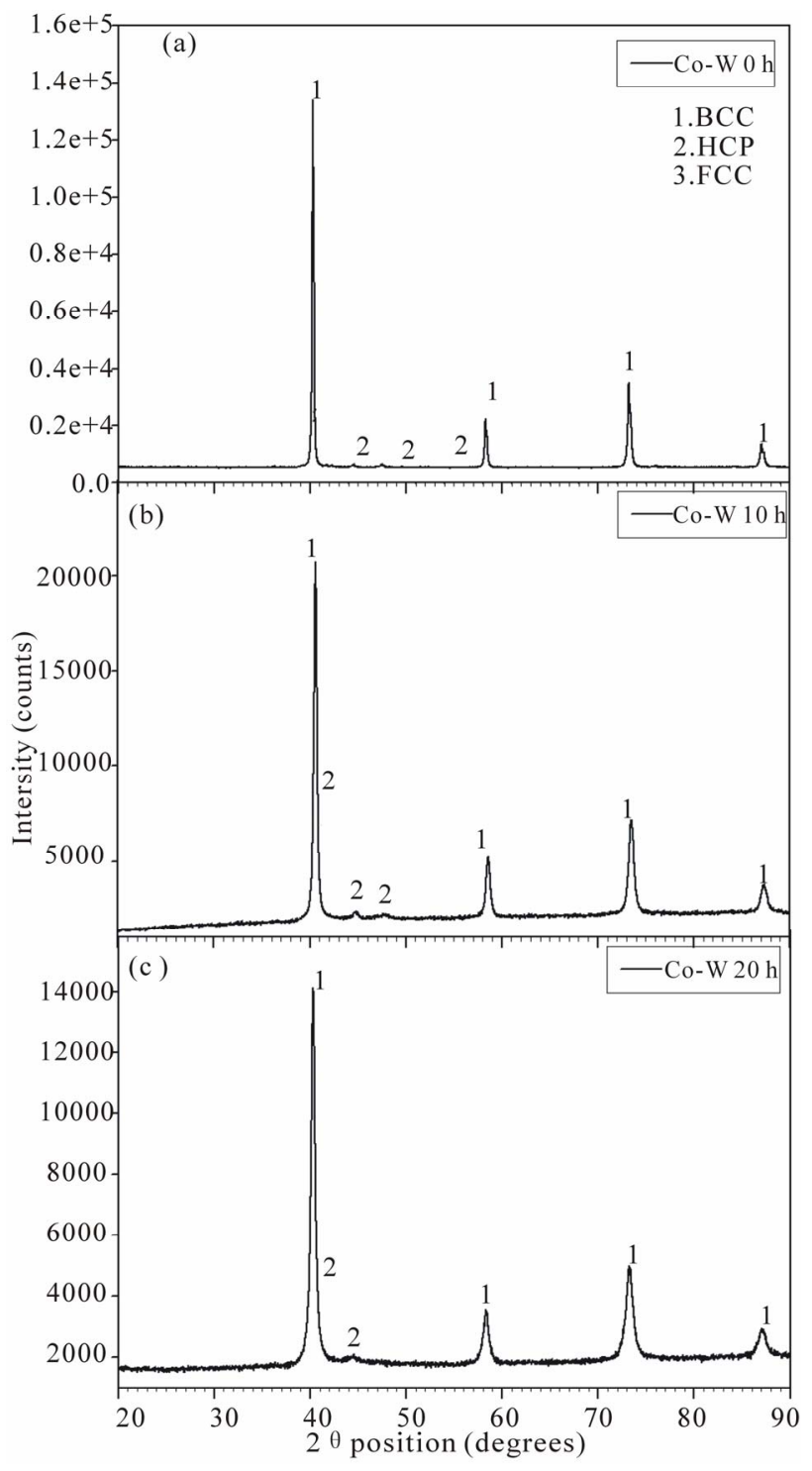

Figure 3. XRD patterns of (a) 0, (b) 10, and (c) $20 \mathrm{~h}$ ball milled Co-W powders.

Other than quicker grain refinement, the above properties imply that $\mathrm{W}$ is expected to have higher resistance to deformation during BM compared to Co.

Figure 4 presents the XRD patterns of $1200^{\circ} \mathrm{C}$ compacts, though the results for unmilled powder was only shown for comparison since it has been discussed in Figure 2(c). The XRD patterns of annealed 10 and $20 \mathrm{~h}$ ball milled compacts show similar phases as shown in Figures 4(b) and (c), though the peak intensities remains slightly higher for the $10 \mathrm{~h}$ milled compacts. Furthermore, the detected phases were alike in crystal structure, HCP and RHL (rhombohedral), though their corresponding lattice parameters varied as indicated in Table 1. This variation from the reported lattice parameters of equilibrium phases such as $\mathrm{RHL} \mathrm{Co}_{7} \mathrm{~W}_{6}(\mathrm{a}=4.751, \mathrm{c}=25.670 \AA)$ is attributed to deviation from stoichiometric composition

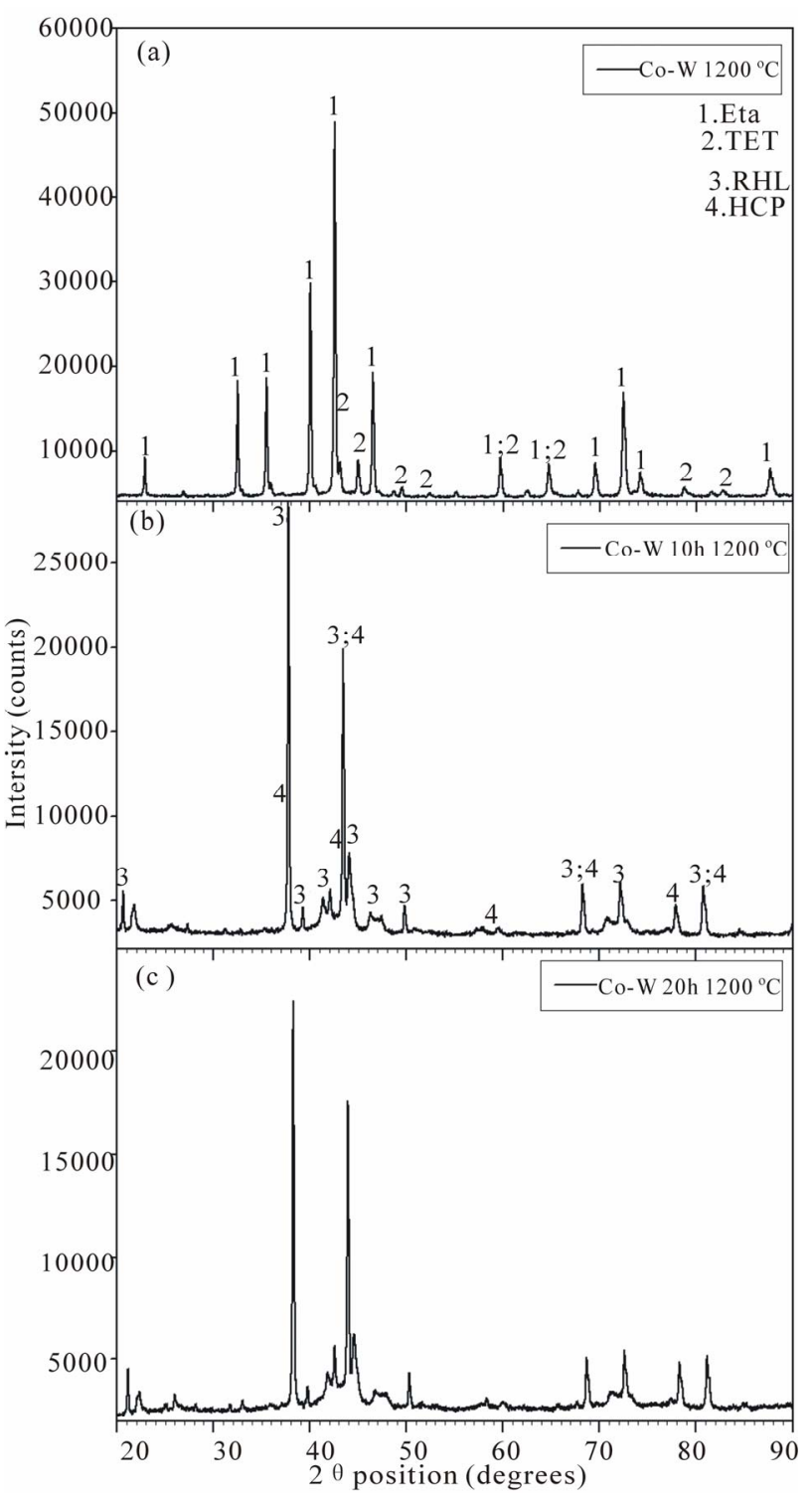

Figure 4. XRD patterns of $1200^{\circ} \mathrm{C}$ annealed compacted powder unmilled (a), after $10 \mathrm{~h}$ (b) and $20 \mathrm{~h}$ (c) ball milling.

as a consequence of $\mathrm{BM}$ and subsequent annealing. A similar HCP phase was reported for milled $\mathrm{W}$ powder annealed at $730^{\circ} \mathrm{C}[16], 1000^{\circ} \mathrm{C}$ [14] and W-Ni compact milled-annealed at $1400^{\circ} \mathrm{C}[16]$. The agility of $\mathrm{BM}$ creates fresh surfaces of fine powder particles which promotes high diffusion rate during high temperature annealing. To date, solid state alloying of metal powders at lower temperatures (induced by BM process) is still a controversial topic, because powders produced by BM have to be shaped and sintered into products. As a result, thermal treatment dictates the final structure and properties of the product. However, mechanism of alloying elemental powders during $\mathrm{BM}$ is vastly different to those milled under the presence of interstitial elements such as $\mathrm{C}, \mathrm{N}, \mathrm{O}$ to form carbides, nitrides and oxides. In pure elementals, 
welding of fresh surfaces is highly possible while diffusion may be the process for the formation of carbides, nitrides and oxides. Therefore, actual alloying of binary alloy occurs by annealing or sintering of powders, while $\mathrm{BM}$ influences the process by changing the surface properties of the particles.

\section{Conclusion}

Despite broadening and shortening of XRD peaks, no alloying was observed upon 10 and $20 \mathrm{~h}$ BM of Co-W powder mixtures. Even if BM did not yield significant crystal changes in $\mathrm{W}$ and Co ground state structures, its effect is evident during subsequent annealing. An eta phase is obtained for the first time from unmilledannealed $\mathrm{Co}-\mathrm{W}$ powder mixture in the absence of interstitial elements like carbon, while the milled counterpart yielded the rhombohedral $\mathrm{Co}_{7} \mathrm{~W}_{6}$-type phase with composition deviated from stoichiometric value. Larger deviation corresponded with longer milled products. In addition, HCP Co-W solid solutions with slightly different lattice parameters were obtained from annealed powders milled for both periods.

\section{REFERENCES}

[1] M. Donten and Z. Stojek, "Pulse Electroplating of Richin-Tungsten Thin Layers of Amorphous Co-W Alloys," Journal of Applied Electrochemistry, Vol. 26, No. 6, 1996, pp. 665-672. doi:10.1007/BF00253466

[2] D. Z. Grabco, I. A. Dikusar, V. I. Petrenko, E. E. Harea and O. A. Shikimaka, "Micromechanical Properties of Co-W Alloys Electrodeposited under Pulse Conditions," Surface Engineering of Applied Electrochemistry, Vol. 43, No. 1, 2007, pp. 11-17. doi:10.3103/S1068375507010024

[3] S. S. Grabchikov and A. M. Yaskovich, "Effect of the Structure of Amorphous Electrodeposited Ni-W and NiCo-W Alloys on Their Crystallization," Russian Metallurgy, Vol. 2006, No. 1, 2006, pp. 56-60. doi:10.1134/S0036029506010101

[4] Z. Guo, X. Zhu, D. Zhai and X. Yang, "Electrodeposition of Ni-W Amorphous Alloy and Ni-W-SiC Composite Deposits," Journal of Materials Science and Technology, Vol. 16, No. 2, 2000, pp. 323-326.

[5] C. Borgia, T. Scharowsky, A. Furrer, C. Solenthaler and R. Spolenak, "A Combinational Study on the Influence of Elemental Composition and Heat Treatment on the Phase Composition, Microstructure and Mechanical Properties of Ni-W Alloy Thin Films," Acta Materialia, Vol. 59, No. 1, 2011, pp. 386-399. doi:10.1016/j.actamat.2010.09.045

[6] B. Yang, G. Qin, W. Pei, Y. Ren, N. Xiao and X. Zhao, "Abnormal Saturation Magnetization Dependency on W Content for Co-W Thin Films," Acta Metalligica Sinica, Vol. 23, No. 1, 2010, pp. 8-12.

[7] M. Mulukutla, V. K. Kommineni and S. P. Harimkar, "Pulsed Electrodeposition of Co-W Amorphous and Crystalline Coatings," Applied Surface Science, Vol. 258, No.
7, 2012, pp. 2886-2893. doi:10.1016/j.apsusc.2011.11.002

[8] K. Wikiel and J. Osteryoung, "Voltammetric Study of Plating Baths for Electrodeposition of Co-W Amorphous Alloys," Journal of Applied Electrochemistry, Vol. 22, No. 6, 1992, pp. 506-511. doi:10.1007/BF01024089

[9] S. Bolokang, C. Bangayayi and M. Phasha, "Effect of C and Milling Parameters on the Synthesis of WC Powders by Mechanical Alloying," International Journal of Refractory Metals and Hard Materials, Vol. 28, No. 2, 2010 , pp. 211-216. doi:10.1016/j.ijrmhm.2009.09.006

[10] K. F. Kobayashi and H. Kawaguchi, "Amorphization of Al-Cr Atomized Powder by Mechanical Alloying," Materials Science and Engineering A, Vol. 181-182, 1994, pp. 1253-1257. doi:10.1016/0921-5093(94)90841-9

[11] A. Karin, A. Bonefačić and D. Dužević, "Phase Transformation in Pressed Cobalt Powder," Journal of Physics F: Metal Physics, Vol. 14, No. 11, 1984, pp. 2781-2786. doi: 10.1088/0305-4608/14/11/030

[12] A. S. Bolokang, M. J. Phasha, D. E. Motaung and S. Bhero, "Effect of Mechanical Milling and Cold Pressing on Co Powder," Journal of Metallurgy, Vol. 2012, 2012, Article ID: 290873. doi:10.1155/2012/290873

[13] S. D. De la Torre, K. N. Ishihara and P. H. Shingu, "Synthesis of SnTe by Repeated Cold-Pressing," Materials Science and Engineering A, Vol. 266, No. 1-2, 1999, pp. 37-43. doi:10.1016/S0921-5093(99)00043-X

[14] A. S. Bolokang, M. J. Phasha, D. E. Motaung and S. Bhero, "Metastable Phases in the Co-W System Traced from Elemental Co and W Powders," International Journal of Refractory Metals and Hard Materials, Vol. 31, 2012, pp. 274-280. doi:10.1016/j.ijrmhm.2011.12.012

[15] A. S. Bolokang, M. J. Phasha, K. Maweja and S. Bhero, "Structural Characterization of Mechanically Milled and Annealed Tungsten Powder," Powder Technology, Vol. 225, 2012, pp. 27-31. doi:10.1016/j.powtec.2012.03.028

[16] K. Maweja, M. J. Phasha and L. J. Choenyane, "Thermal Stability and Magnetic Saturation of Annealed NickelTungsten and Tungsten Milled Powders," International Journal of Refractory Metals and Hard Materials, Vol. 30, No. 1, 2012, pp. 78-84. doi:10.1016/j.ijrmhm.2011.07.005

[17] C. Borgia, T. Scharowsky, A. Furrer, C. Solenthaler and R. Spolenak, "A Combinational Study on the Influence of Elemental Composition And Heat Treatment on the Phase Composition, Microstructure And Mechanical Properties of Ni-W Alloy Thin Films," ActaMaterialia, Vol. 59, No. 1, 2011, pp. 386-399. doi:10.1016/j.actamat.2010.09.045

[18] D. Oleszak, V. K. Portnoy and H. Matyja, "Formation of Metastable Phases in Ni-43.5 at \% Mo Powder Mixtures during Mechanical Alloying and after Heat Treatment," Philosophical Magazine, Vol. 76, No. 4, 1997, pp. 639649. doi:10.1080/01418639708241130

[19] N. A. Dubrovinskaia, L. S. Dubrovinsky, S. K. Saxena, M. Selleby and B. Sundman, "Thermal Expansion and Compressibility of $\mathrm{Co}_{6} \mathrm{~W}_{6} \mathrm{C}$," Journal of Alloys and Compounds, Vol. 285, No. 1-2, 1999, pp. 242-245. 
doi:10.1016/S0925-8388(98)00932-3

[20] P. Bracconi and L. C. Dufour, "Investigation of Cobalt (II)-Tungsten (VI)-Oxide Reduction in Hydrogen," Metallurgical Transaction A, Vol. 7, No. 3, 1976, pp. 321-
327.

[21] R, German, "Powder Metallurgy Science," Metal Powder Industry Federation, Princeton, 1994. 